\title{
Alterations in cortical and extrastriatal subcortical dopamine function in schizophrenia: systematic review and meta-analysis of imaging studies
}

Joseph Kambeitz, Anissa Abi-Dargham, Shitij Kapur and Oliver D. Howes

\section{Background}

The hypothesis that cortical dopaminergic alterations underlie aspects of schizophrenia has been highly influential.

\section{Aims \\ To bring together and evaluate the imaging evidence for dopaminergic alterations in cortical and other extrastriatal regions in schizophrenia.}

\section{Method}

Electronic databases were searched for in vivo molecular studies of extrastriatal dopaminergic function in schizophrenia. Twenty-three studies (278 patients and 265 controls) were identified. Clinicodemographic and imaging variables were extracted and effect sizes determined for the dopaminergic measures. There were sufficient data to permit meta-analyses for the temporal cortex, thalamus and substantia nigra but not for other regions.

\section{Results}

The meta-analysis of dopamine $D_{2} / D_{3}$ receptor availability found summary effect sizes of $d=-0.32(95 \% \mathrm{Cl}-0.68$ to $0.03)$ for the thalamus, $d=-0.23(95 \% \mathrm{Cl}-0.54$ to 0.07$)$ for the temporal cortex and $d=0.04(95 \% \mathrm{Cl}-0.92$ to 0.99$)$ for the substantia nigra. Confidence intervals were wide and all included no difference between groups. Evidence for other measures/regions is limited because of the small number of studies and in some instances inconsistent findings, although significant differences were reported for $D_{2} / D_{3}$ receptors in the cingulate and uncus, for $D_{1}$ receptors in the prefrontal cortex and for dopamine transporter availability in the thalamus.

\section{Conclusions}

There is a relative paucity of direct evidence for cortical dopaminergic alterations in schizophrenia, and findings are inconclusive. This is surprising given the wide influence of the hypothesis. Large, well-controlled studies in drug-naive patients are warranted to definitively test this hypothesis.

\section{Declaration of interest}

O.D.H has consulted for and/or spoken at events organised by AstraZeneca, Bristol-Myers Squibb, Janssen, Eli Lilly, Roche and Sunovion. A.A.-D. has consulted or given lectures for Sunovion, Shire, and Bristol-Myers Squibb/Otsuka. S.K. has received grant support from AstraZeneca and GlaxoSmithKline and has served as consultant and/or speaker for AstraZeneca, Bioline, Bristol-Myers Squibb/Otsuka, Eli Lilly, Janssen (Johnson \& Johnson), Lundbeck, Neuro-Search, Pfizer, Roche, Servier, and Solvay/Wyeth.
Schizophrenia affects about $1 \%$ of the population, ${ }^{1}$ and is a major cause of global disease burden. ${ }^{2}$ The investigation of the biological underpinnings of the disease are crucial steps to the rational development of more effective treatments for the illness. ${ }^{3,4}$ The dopamine hypothesis of schizophrenia has been an enduring theory of the neurobiology underlying the disorder. ${ }^{5,6}$ In its earliest instance it was a biochemical hypothesis (increased dopamine transmission) without a precise molecular or anatomical specificity. In the past two decades the hypothesis has been refined to enhance its molecular and anatomical specificity. The newer conceptualisation of the hypothesis postulates an increase in dopamine release and synthesis capacity in the striatum and links this to positive symptoms. ${ }^{7,8}$ The metaanalytic evidence for this is robust, with an effect size of 0.8 , and has been recently reviewed. ${ }^{9}$ The hypothesis has also evolved to link low dopamine activity in cortical regions to negative symptoms and cognitive deficits. ${ }^{7,8}$ This has been highly influential - for example, the paper ${ }^{7}$ proposing that low cortical dopamine activity is primary and causes deficit symptoms has attracted nearly 1000 citations to date (see http://apps. webofknowledge.com/). However, to our knowledge the direct evidence for dopaminergic alterations in cortical and other extrastriatal regions has not been previously systematically reviewed and this thus forms the focus of our meta-analysis.

Developments in molecular imaging in the past two decades have enabled the regional specificity and nature of dopaminergic dysfunction to be studied in vivo in patients with schizophrenia. $^{7,8,10}$ The initial studies focused on the striatum ${ }^{11-13}$ and there have now been over 50 studies that have investigated striatal dopamine function in schizophrenia. ${ }^{9}$ The in vivo investigation of extrastriatal dopamine function has been technically more complicated, not least because dopaminergic projections to other regions are sparse compared with the striatum. However, the development of high-affinity selective tracers such as [11C]-FLB $457,{ }^{14}$ [18F]-fallypride, ${ }^{15}$ [123I]-epidepride ${ }^{16}$ and [11C]-(+)-4-propyl-9-hydroxynaphthoxazine (PHNO) ${ }^{17}$ has enabled the in vivo investigation of $\mathrm{D}_{2} / \mathrm{D}_{3}$ receptors in extrastriatal regions, and the tracers [11C]-NNC and [11C]-SCH23390 have enabled this for $\mathrm{D}_{1}$ receptors. ${ }^{18,19}$ Besides dopamine receptors, tracers with specific binding to the dopamine transporter or that use radiolabelled-dihydroxyphenylalanine (DOPA) to index dopamine synthesis capacity have been used to investigate different aspects of dopaminergic neurotransmission in extrastriatal regions. ${ }^{18} \mathrm{We}$ recently conducted a meta-analysis of striatal dopaminergic function in schizophrenia. ${ }^{9}$ This found that presynaptic dopamine function - specifically dopamine synthesis capacity, dopamine release and baseline synaptic dopamine levels - were highly significantly elevated in schizophrenia with a large effect size (Cohen's $d=0.8$ ). There was also an elevation in $\mathrm{D}_{2} / \mathrm{D}_{3}$ receptor availability but this was relatively small (Cohen's $d=0.24$ ) and inconsistent. In contrast there was no evidence of an alteration in dopamine transporter or $D_{1}$ receptor availability. We now aim to systematically review the extrastriatal molecular imaging findings in schizophrenia and, where there are sufficient studies, conduct a meta-analysis to evaluate the evidence for dopaminergic dysfunction outside of the striatum. 


\section{Method}

\section{Search and selection strategy}

The entire PubMed, PsycINFO and MEDLINE electronic databases were searched from 1 January 1950 up to 31 December 2012. Initially, studies were screened based on a search using a comprehensive search term [("Positron Emission Tomography" OR "PET" OR "Single photon emission tomography" OR "SPET" OR "Single Photon Emission Computed Tomography" OR "SPECT") AND (“dopamine") AND ("schizophrenia” OR "psychosis" OR "psychotic" OR "schizophreniform”) AND ("thalamus" OR "thalamic" OR "cingulate" OR "cortex" OR "frontal” OR "prefrontal” OR "temporal” OR "parietal” OR "midbrain" OR "substantia nigra" OR "hippocampus" OR "amygdala") AND (1950:2012/12/31[DP])]. Only publications in peer-reviewed journals in English language were considered. To be included in the meta-analysis a paper needed to report in vivo positron emission tomography (PET) or single photon emission computed tomography (SPECT)/single photon emission tomography (SPET) imaging findings of extrastriatal dopaminergic function in patients with schizophrenia and a control group with sufficient data to enable the mean and standard deviations for both groups to be calculated. Studies were excluded if healthy controls had any neurological or psychiatric disease or if patients had any neurological condition or psychiatric disease other than a psychotic disorder. Current antipsychotic treatment was an exclusion criterion for the studies of $\mathrm{D}_{2} / \mathrm{D}_{3}$ receptors, because it is clear this affects dopamine receptor binding potential. ${ }^{20}$

Where the studies reported overlapping samples, the paper reporting the largest sample size was used and the other paper excluded to prevent double counting. For the region of the brain sampled, if two papers reported different definitions of regions applied to the same data, the paper reporting the regional definition closest to that used by other papers in the meta-analysis was used to ensure greatest comparability. As prior antipsychotic treatment may influence dopaminergic indices, ${ }^{21}$ data were presented combined and, where available, separately for patients who had previously received antipsychotic treatment and for patients who were antipsychotic-naive to enable findings to be compared.

\section{Data extraction}

The main outcome measure was the difference in the dopaminergic imaging parameter between healthy controls and patients with schizophrenia. The following additional information was extracted from all the studies: names of the authors, year of publication, population characteristics of the healthy control and patient groups (group size, age, gender, antipsychotic use, diagnosis, symptom ratings), characteristics of the imaging (radiotracer, other methodological factors reported), scanner characteristics (scanner type and resolution), and modelling method. The data were extracted by one author (J.K.) and checked twice additionally to assure accuracy. In case of uncertainties data were checked by another author (O.D.H.) and consensus reached. As there are no established criteria for assessing the quality of molecular imaging studies, we have summarised methodological aspects of each study to enable individual judgements to be made (see online Tables DS1 and DS2).

\section{Data analysis}

A minimum of five studies was required to proceed with the metaanalysis as findings become less reliable with fewer studies. ${ }^{22}$ The
$\mathrm{R}$ statistical programming language ${ }^{23}$ version 2.10.1 on Mac OS-X (version 10.6.8) with the package 'metafor' ${ }^{24}$ was used to conduct meta-analyses as well as power calculations. ${ }^{25}$ A significance level of $P<0.05$ (two-tailed) was used for all analyses.

The standardised effect sizes of the individual studies were entered in a random-effects meta-analytic model, ${ }^{26,27}$ which does not assume homogeneity among studies. The summary effect sizes (cohen's $d$ ) were computed using a restricted maximumlikelihood estimator. ${ }^{28}$ Heterogeneity was assessed in the studies by calculating the $I^{2}$ value, which is a sample size independent measure that describes the percentage of total variation across studies that is as a result of heterogeneity rather than chance. ${ }^{29}$ As a guideline, $I^{2}$ values of $0-40 \%$ indicate heterogeneity that is not important, 30-60\% moderate heterogeneity, 50-90\% substantial heterogeneity and $75-100 \%$ considerable heterogeneity $^{29}$ (for further details see Higgins \& Green $^{30}$ ). Pre-specified analyses to evaluate potential sources of bias and sensitivity analyses were conducted as follows. To examine the potential effect of prior antipsychotic treatment, the analysis was repeated for subgroups defined by treatment history (antipsychotic-naive or previously treated) to determine whether this influenced the findings. The potential effects of publication year, gender and the age of participants was evaluated using meta-regression. ${ }^{26}$ To account for differences in precision, studies were weighted by their sample size before being entered in a regression model with the variable of interest as a predictor for the standardised effect sizes.

Publication bias was evaluated by inspection of the funnel plot (a plot of effect sizes on the $x$-axis against standard error $(1 /$ precision $))$ for evidence of asymmetry. Publication bias is suggested if studies with small precision and small effect size are absent. Publication bias was further evaluated using Egger's test. ${ }^{31}$ To assess the influence of individual studies on the estimated summary effect size, a post hoc leave-one-out approach was applied by re-running the meta-analysis after leaving out one different individual study at successive iterations.

\section{Results}

After initial identification of 242 articles, 219 articles were excluded (see online Fig. DS1 for reasons for excluding studies). This resulted in a sample of 23 studies of extrastriatal dopamine in schizophrenia including 13 studies of $\mathrm{D}_{2} / \mathrm{D}_{3}$ receptors, 4 studies of $D_{1}$ receptors, 5 studies of dopamine synthesis capacity and 1 study of dopamine transporter availability. The most commonly used outcome measure was the binding potential relative to the non-displaceable compartment $\left(\mathrm{BP}_{\mathrm{ND}}\right)$. The $\mathrm{BP}_{\mathrm{ND}}$ is the equilibrium ratio of the concentration of specifically bound radioligand relative to the sum of the free and non-specifically bound radioligand, estimated from activity in a reference region. Alternatively the equilibrium ratio relative to either the total or free (unbound) concentration of radioligand in plasma can be used, denoted as $\mathrm{BP}_{\mathrm{P}}$ or $\mathrm{BP}_{\mathrm{F}}$ respectively. ${ }^{32}$ The $\mathrm{BP}_{\mathrm{ND}}, \mathrm{BP}_{\mathrm{P}}$ and $\mathrm{BP}_{\mathrm{F}}$ are all proportional to the concentration of receptors available to be bound in the tissue of interest. ${ }^{32}$ As all the studies reported $\mathrm{BP}_{\mathrm{ND}}$ and only two studies reported $\mathrm{BP}_{\mathrm{P}}$ and $\mathrm{BP}_{\mathrm{F}}$, we used $\mathrm{BP}_{\mathrm{ND}}$ for the meta-analyses. For the meta-analysis of thalamic $D_{2} / D_{3}$ receptors some studies reported results of overlapping samples, in which case the study with the largest sample was selected for inclusion. Thus, Buchsbaum et $a l^{33}$ was excluded as there was sample overlap with Lehrer et al. ${ }^{34}$ Also there was sample overlap between Yasuno et $a l^{35}$ Yasuno et $a l^{36}$ and Suhara et al. ${ }^{37}$ Only Suhara $e a^{37}$ was included as the thalamic region used was closest to that of other studies in the available literature. For Talvik et al ${ }^{38}$ and Talvik et $a l^{39}$ there appeared to be sample overlap. As attempts 
to contact the authors to verify this were unsuccessful, we included only one of both studies in each meta-analysis. We included Talvik $e a^{38}$ in the meta-analysis of the temporal cortex and Talvik et $a l^{39}$ for the meta-analysis of the thalamus to maximise sample size and to avoid potential sample overlap. Kegeles et $a l^{40}$ applied the simplified reference tissue model (SRTM) and a two-tissue compartmental model to the imaging data and reported $\mathrm{D}_{2} / \mathrm{D}_{3} \mathrm{BP}_{\mathrm{ND}}$ for both. As most other studies in this analysis applied an SRTM approach, we selected these data from Kegeles et $a l^{40}$ to ensure the modelling approach was the same across studies. Kegeles et al ${ }^{40}$ reported $\mathrm{D}_{2} / \mathrm{D}_{3} \mathrm{BP}_{\mathrm{ND}}$ values corrected for partial volume effects. These were entered in the analysis rather than uncorrected values.

The characteristics of the participants for the included studies are shown in Table DS1 and the imaging methods are summarised in Table DS2. There were sufficient studies to conduct separate meta-analyses for the $D_{2} / D_{3}$ receptor availability in the thalamus, the substantia nigra and for the temporal cortex. There were too few studies to enable reliable meta-analysis of findings for other regions or for other measures of dopaminergic function - for these studies we have plotted the individual effect sizes to aid comparison and evaluation of trends and summarised the findings below.

\section{$D_{2} / D_{3}$ receptor availability}

\section{Thalamus}

Eight studies comprising 138 patients with schizophrenia and 126 healthy controls met inclusion criteria for the meta-analysis. The summary effect size for thalamic $\mathrm{D}_{2} / \mathrm{D}_{3} \mathrm{BP}_{\mathrm{ND}}$ between patients with schizophrenia and healthy controls was $d=-0.32$ but did not reach significance $(95 \%$ CI -0.68 to $0.03, z=-1.787$, $P=0.07, I^{2}=48.79 \%, 95 \%$ CI $0-84.25 \%$, see Fig. 1(a)). Inspection of the funnel plot (Fig. 1(b)) and Egger's test $(z=-0.6727$, $P=0.5011)$ did not show evidence for publication bias. The sensitivity analysis for the thalamus showed a significant summary effect size for two out of eight iterations. There was a significant summary effect size when Kegeles et al ${ }^{40}$ or Glenthoj et al ${ }^{41}$ were excluded from the meta-analysis. Meta-regression analysis did not show evidence for an effect of year of publication $(\beta=0.0275, F(1,6)=0.1591, P=0.7038$, see Fig.1 $(c))$, gender $(\beta=1.257, F(1,4)=0.1675, \quad P=0.7033)$ or age $(\beta=-0.0695$, $F(1,5)=0.3863, P=0.5615)$ on the estimated summary effect size. Restricting the meta-analysis to the five studies that included participants with previous exposure to antipsychotic medication showed a non-significant effect size of $d=-0.34$ (95\% CI -0.78 to $0.1, z=-1.5058, P=0.1, I^{2}=42.83 \%, 95 \%$ CI $0-89.38 \%$ ). The studies of medication-naive participants showed effect sizes of $0.35,{ }^{41}-0.62^{39}$ and $-0.77 .^{37}$ However, there were too few studies of medication-naive participants to permit meta-analysis.

\section{Temporal cortex}

We included six studies in the meta-analysis comprising 84 patients with schizophrenia and 86 healthy controls. There was no evidence for a reduction in $\mathrm{D}_{2} / \mathrm{D}_{3}$ availability in the temporal cortex in patients with schizophrenia $(d=-0.23,95 \%$ CI -0.54 to $0.07, z=-1.5097, P=0.1, I^{2}=0 \%, 95 \%$ CI $0-67.2 \%$, see Fig. 2(a)). Inspection of the funnel plot (Fig. 2(b)) and Egger's test $(z=0.6917, P=0.4891)$ did not show evidence for publication bias. The sensitivity analysis for the temporal cortex did not show a significant summary effect size in any of the six iterations. Meta-regression analysis did not show evidence for an effect of year of publication $(\beta=-0.0297, F(1,4)=0.7138, P=0.4458$, see Fig. $2(\mathrm{c}))$, gender $(\beta=-1.1818, F(1,3)=2.2341, P=0.2319)$ or age $(\beta=0.0535, F(1,4)=1.4834, P=0.2902)$ on the estimated summary effect size. The meta-analysis of the temporal cortex included three studies in drug-free patients that reported effect sizes of $d=-0.42,{ }^{40} d=-0.33^{44}$ and $d=0.0 .^{45}$ The studies in drug-naive participants reported comparable effect sizes of $d=0.49,{ }^{37} d=-0.12^{41}$ and $d=0.27 .^{38}$ The small number of studies did not allow further analysis of the moderating effect of medication in this region.

\section{Substantia nigra}

We included five studies in the meta-analysis comprising 61 patients with schizophrenia and 72 healthy controls. There was no significant difference between patients with schizophrenia and healthy controls $(d=0.04,95 \% \mathrm{CI}-0.92$ to $0.99, z=0.075$, $P=0.9, \quad I^{2}=84.8 \%, \quad 95 \%$ CI $52.89-98.49 \%$, see Fig. 3(a)). Inspection of the funnel plot (Fig. 3(b)) and Egger's test $(z=-0.79, P=0.43)$ did not show evidence for a publication bias. The sensitivity analysis for the substantia nigra did not show a significant summary effect size in any of the five iterations. Meta-regression did not show evidence for an effect of year of publication $(\beta=0.1649, \quad F(1,3)=0.3381, \quad P=0.6018$, see Fig. $3(\mathrm{c}))$, gender $(\beta=-0.6768, F(1,3)=0.0375, P=0.8587)$ or age $(\beta=0.0085, \quad F(1,3)=0.0008, \quad P=0.9793) \quad$ on the estimated summary effect size. Also after excluding the one study of drugnaive patients there was still no significant effect $(d=-0.04$, $95 \%$ CI -1.31 to $1.22, z=-0.0628, P=0.9, I^{2}=88.59 \%, 95 \%$ CI $60.53-99.28 \%)$.

\section{Findings in the other regions}

There were seven studies with a total of 109 patients and 120 controls investigating $\mathrm{D}_{2} / \mathrm{D}_{3} \quad \mathrm{BP}_{\mathrm{ND}}$ in 11 other extrastriatal regions. The effect sizes for these regions are shown by study in Fig. 4. Out of three studies of the anterior cingulate, one reported a significant decrease of $\mathrm{D}_{2} / \mathrm{D}_{3} \mathrm{BP}_{\mathrm{ND}}$ in patients with schizophrenia $^{36}$ and two reported no significant change. ${ }^{38,44}$ One study reported a significant decrease of $\mathrm{D}_{2} / \mathrm{D}_{3} \mathrm{BP}_{\mathrm{ND}}$ in the uncus. ${ }^{44}$ There were no significant changes reported in the entorhinal cortex,${ }^{40}$ the hippocampus, ${ }^{37,40,44}$ the amygdala, ${ }^{40,44}$ the prefrontal cortex, ${ }^{36,38,41}$ the occipital cortex, ${ }^{37}$ the parietal cortex, ${ }^{36}$ the insula $^{40}$ or the globus pallidum. ${ }^{43}$

\section{Dopamine synthesis capacity}

Four studies investigated presynaptic dopamine synthesis capacity outside the striatum. ${ }^{4-49}$ These studies report data from 58 healthy controls and 53 patients in 12 different regions (Fig. $4(a))$. There were significant changes in two regions in one study. This study reported a significant decrease in the middle frontal cortex and a significant increase in the posterior cingulate. ${ }^{48}$

\section{$D_{1}$ receptor availability}

There were four studies of $D_{1}$ receptor availability including a total of 55 patients and 68 controls and reporting results for 15 different regions ${ }^{21,50-52}$ (summarised in Fig. 4(b)). There were three reports of significant changes in the prefrontal cortex, and one report of no significant change. Abi-Dargham et al ${ }^{52}$ reported a significant increase in prefrontal $\mathrm{D}_{1} \mathrm{BP}_{\mathrm{ND}}$ in patients with schizophrenia. However, Okubo et al ${ }^{50}$ report a significant decrease. Both of these studies included drug-naive and previously drug-treated patients. The most recent study reported a significant elevation in $D_{1}$ receptor availability in antipsychotic-naive patients, but no difference from controls in previously antipsychotic-treated patients. ${ }^{21}$ No other extrastriatal regions showed 
(a)

\begin{tabular}{|c|c|c|c|c|c|c|c|c|}
\hline \multirow[b]{2}{*}{ Study } & \multicolumn{6}{|c|}{$95 \% \mathrm{Cl}$} & \multirow[b]{2}{*}{ Greater in controls } & \multirow{2}{*}{ Greater in schizophrenia } \\
\hline & Year & d & Upper & Lower & $z$-score & $P$ & & \\
\hline Suhara et $a l^{37}$ & 2002 & -0.7660 & -1.5414 & 0.0096 & -1.9357 & 0.0529 & $\longrightarrow$ & \\
\hline Glenthoj et al ${ }^{41}$ & 2006 & 0.3453 & -0.2470 & 0.9376 & 1.1427 & 0.2532 & & $\rightarrow$ \\
\hline Talvik et al ${ }^{39}$ & 2006 & -0.6179 & -1.2964 & 0.0606 & -1.7849 & 0.0743 & & \\
\hline Tuppurainen et al/42 & 2006 & -0.3115 & -1.4085 & 0.7855 & -0.5565 & 0.5778 & & \\
\hline Graff-Guerrero et al ${ }^{43}$ & 2009 & -0.3922 & -1.1684 & 0.3839 & -0.9905 & 0.3219 & & \\
\hline Kessler et al ${ }^{44}$ & 2009 & -0.4788 & -1.3264 & 0.3688 & -1.1072 & 0.2682 & & \\
\hline Kegeles et al ${ }^{40}$ & 2010 & 0.2691 & -0.3315 & 0.8698 & 0.8783 & 0.3798 & & - \\
\hline Lehrer et al ${ }^{34}$ & 2010 & -0.8284 & -1.4247 & -0.2320 & -2.7224 & 0.0065 & — & \\
\hline
\end{tabular}

$\begin{array}{llllll}\text { RE model } & -0.3238 & -0.6790 & 0.0313 & -1.7870 & 0.0739\end{array}$

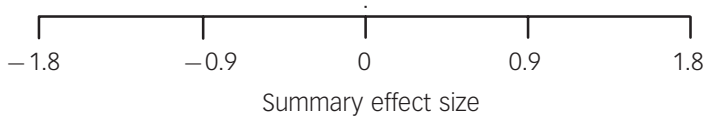

(b)

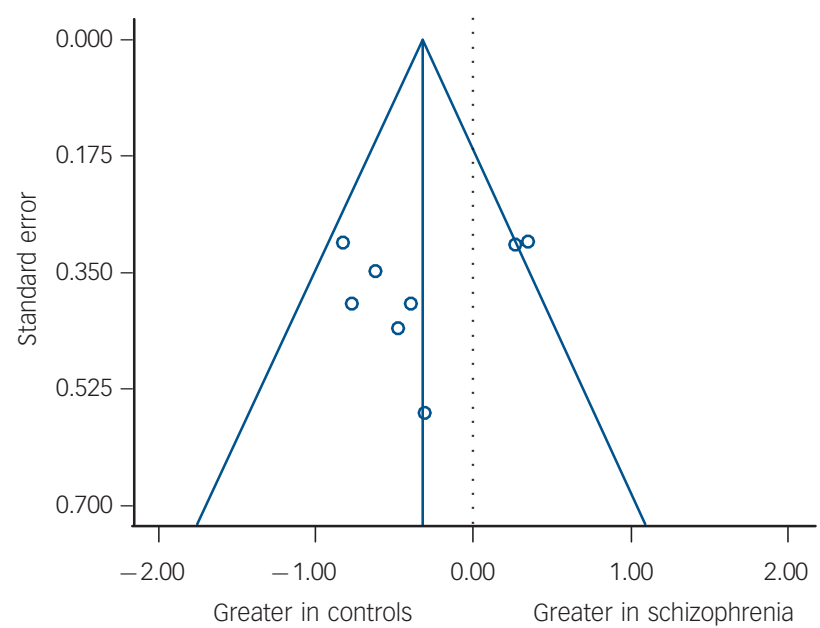

Estimated effect size (c)

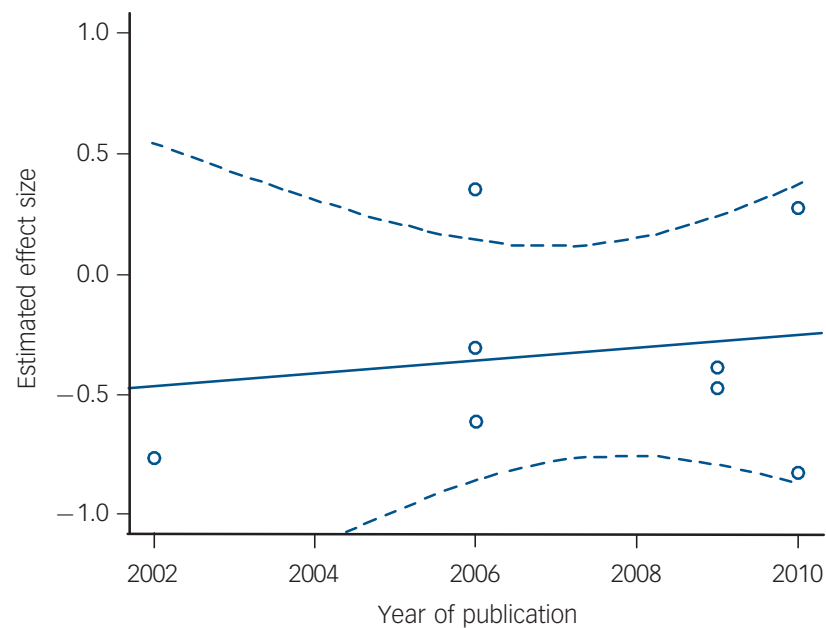

Fig. 1 (a) Forrest plot, (b) funnel plot and (c) meta-regression with year of publication of meta-analysis of thalamic $D_{2} / D_{3} B P_{N D}$.

Error bars represent 95\% confidence intervals; RE model, random-effects model.

significant changes in $\mathrm{D}_{1} \mathrm{BP}_{\mathrm{ND}}$ in schizophrenia in any of these studies.

\section{Dopamine transporter availability}

One study investigated dopamine transporter availability outside the striatum in 12 healthy controls and 8 patients for two regions ${ }^{53}$ (Fig. 4(d)). This study reports a significant increase in the thalamus but no significant change in the substantia nigra.

\section{Discussion}

\section{$D_{2} / D_{3}$ receptor availability}

Our meta-analyses showed small, non-significant reductions in $\mathrm{D}_{2} / \mathrm{D}_{3}$ receptor availability in the thalamus $(d=-0.32, P=0.07)$ and temporal cortex $(d=-0.23, P=0.1)$ in schizophrenia and no significant difference between patients and controls in the substantia nigra $(d=0.04, P=0.9)$. Although these were not statistically significant, it is important to note that the summary estimates were relatively imprecise and the confidence intervals for the thalamus and temporal cortex included moderate-large reductions as well as very small elevations. Furthermore, the leave-one-out sensitivity analysis for the thalamus found that the reduction was significant on two iterations, indicating that the meta-analysis was sensitive to the inclusion of two individual studies, and that the lack of significance should not be considered as conclusively excluding a reduction. This sensitivity could reflect differences in methodology or sample characteristics (see later) and indicates the need for further large studies to conclusively address the issue. Although there were too few studies to permit meta-analysis in other regions, the majority of studies found no significant differences in patients, and where there were significant decreases this was either a sole finding or not replicated in other studies. Thus, overall there do not appear to be marked alterations in $\mathrm{D}_{2} / \mathrm{D}_{3}$ receptor availability in extrastriatal regions but there may be a small reduction in $D_{2} / D_{3}$ availability in the thalamus. The 
(a)

$95 \% \mathrm{Cl}$

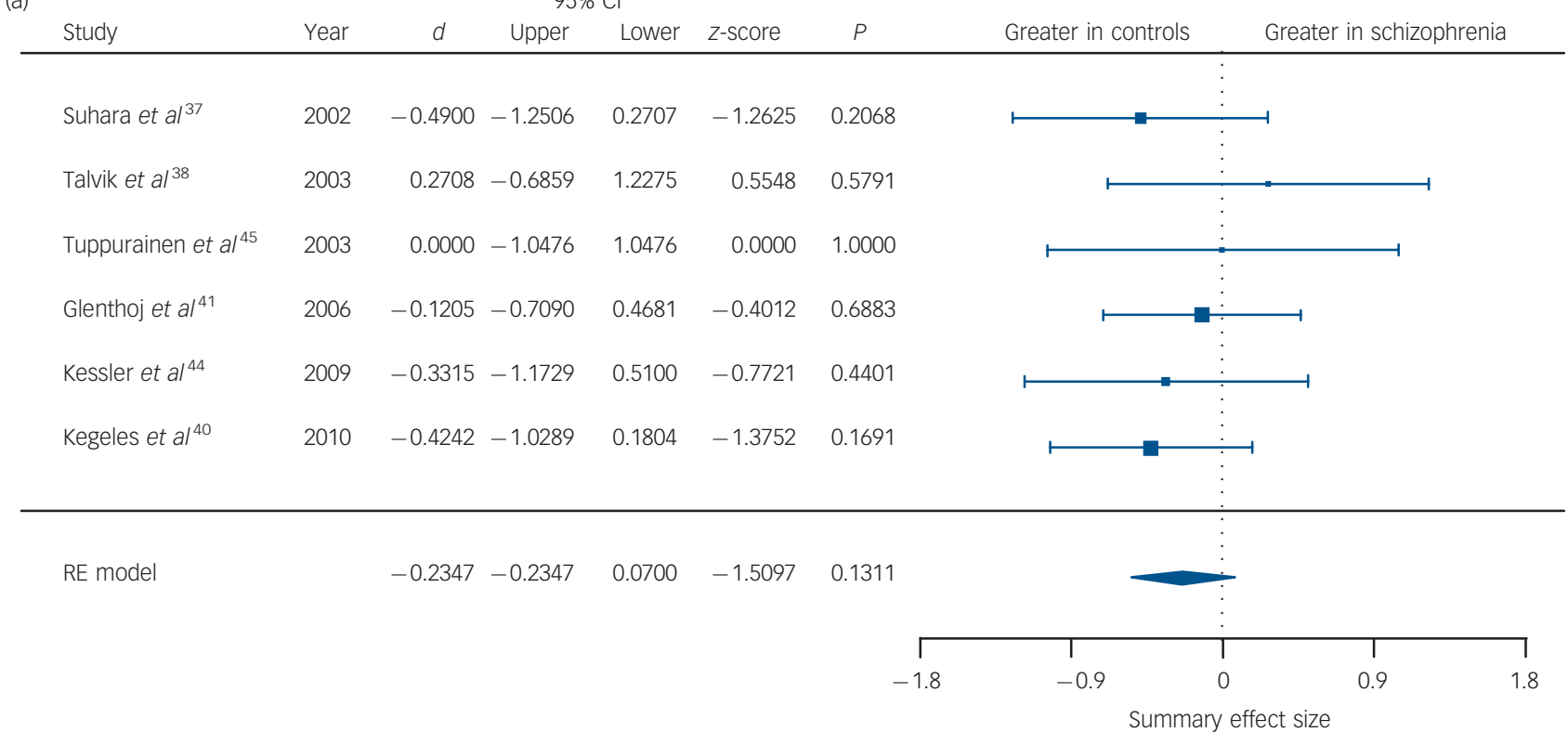

(b)

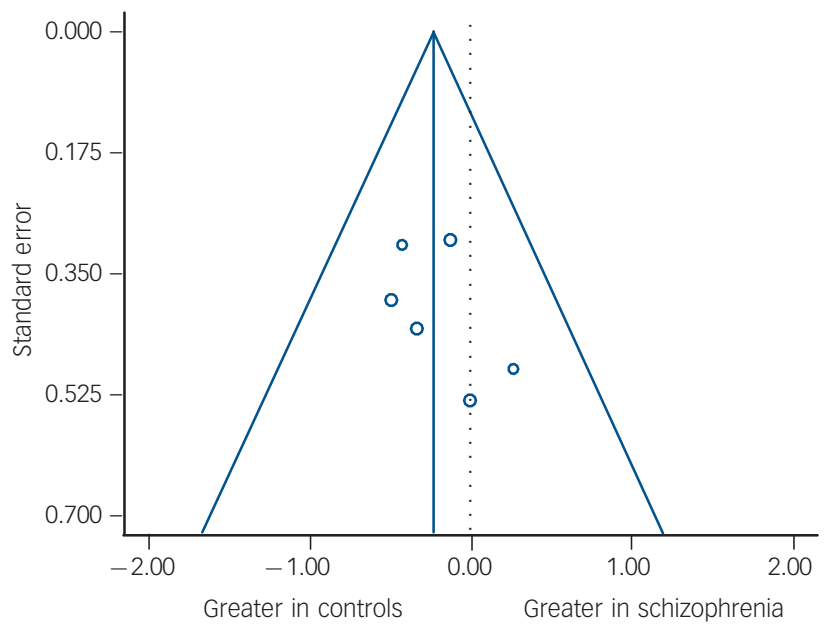

Estimated effect size (c)

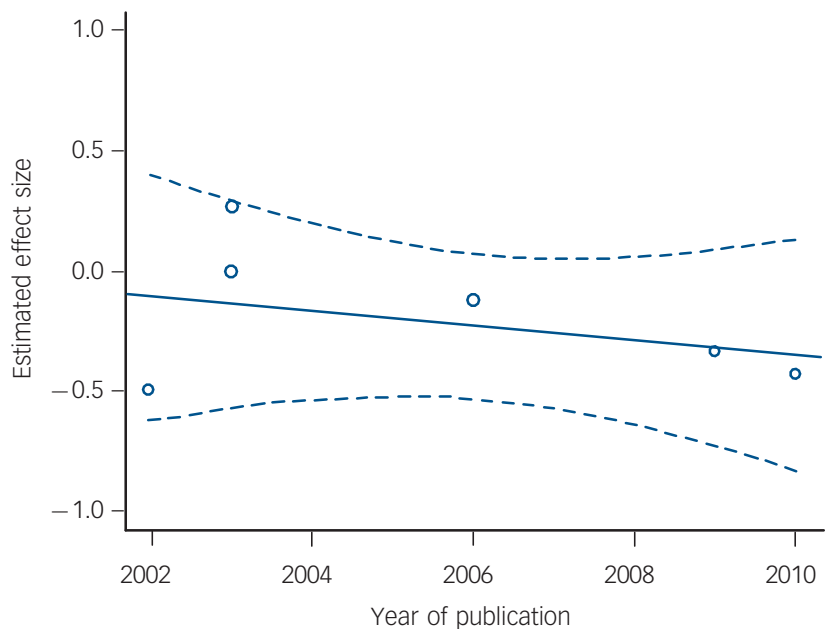

Fig. 2 (a) Forrest plot, (b) funnel plot and (c) meta-regression with year of publication of meta-analysis of temporal $D_{2} / D_{3} B P_{N D}$.

Error bars represent 95\% confidence intervals; RE model, random-effects model.

clinical significance of a small reduction in $\mathrm{D}_{2}$, if it is present, is not clear, and, although one study does report a significant correlation between lower $D_{2} / D_{3}$ receptor availability in subregions of the thalamus and higher symptom severity, ${ }^{35}$ other studies report the opposite relationship ${ }^{38,44}$ or no relationship in these regions. ${ }^{41}$

\section{$D_{1}$ receptor availability}

There were too few studies to permit meta-analysis and findings were inconsistent across studies. A factor that could underlie the inconsistency is suggested by a study in rats comparing the effects of dopamine depletion on the binding of the two tracers used. ${ }^{54}$ This found that although dopamine depletion increased, as expected, the binding of [11C]-NNC, it paradoxically decreased the binding of [11C]-SCH23390. Thus, if this also occurs in humans, low cortical dopamine levels in schizophrenia would be associated with opposite effects on the binding of these tracers. Additionally, antipsychotic treatment has been found to reduce
$\mathrm{D}_{1}$ receptor density, ${ }^{55}$ indicating that prior antipsychotic treatment could be confounded in some studies. A further complicating issue is that both the tracers used in the studies show appreciable binding to 5-hydroxytrptamine $\left(5 \mathrm{HT}_{2 \mathrm{~A}}\right)$ receptors. ${ }^{56}$ In the absence of more selective $\mathrm{D}_{1}$ tracers, blocking studies using selective $5 \mathrm{HT}_{2 \mathrm{~A}}$ or $\mathrm{D}_{1}$ compounds would enable the $\mathrm{D}_{1}$ specific signal to be evaluated. In summary, the available data of frontal $D_{1}$ binding are limited and further studies in drug-naive patients are warranted.

\section{Dopamine transporter availability}

There has been remarkably little investigation of dopamine transporter availability in vivo outside of the striatum. The two findings were of a significant increase in dopamine transporter availability in the thalamus and no difference in the substantia nigra. Also, it is noteworthy that the tracer used shows good test-retest characteristics in both regions, ${ }^{57}$ indicating that measurement is reliable and suggesting that further investigation 
(a)

\begin{tabular}{|c|c|c|c|c|c|c|c|c|}
\hline \multirow[b]{2}{*}{ Study } & \multicolumn{6}{|c|}{ 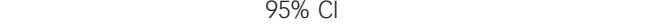 } & \multirow[b]{2}{*}{ Greater in controls } & \multirow[b]{2}{*}{ Greater in schizophrenia } \\
\hline & Year & d & Upper & Lower & z-score & P & & \\
\hline Yasuno et al ${ }^{35}$ & 2004 & 0.2741 & -0.4949 & 1.0430 & 0.6985 & 0.4848 & & - \\
\hline Tuppurainen et al ${ }^{42}$ & 2006 & -1.7195 & -2.9945 & -0.4444 & -2.6430 & 0.0082 & 4 & \\
\hline Graff-Guerrero et al ${ }^{43}$ & 2009 & -0.3922 & -1.1684 & 0.3839 & -0.9905 & 0.3219 & $\longmapsto$ & $\longrightarrow$ \\
\hline Kessler et al ${ }^{44}$ & 2009 & 1.5745 & 0.6180 & 2.5310 & 3.2263 & 0.0013 & & $\longrightarrow$ \\
\hline Kegeles et al ${ }^{40}$ & 2010 & 0.2039 & -0.3956 & 0.8034 & 0.6666 & 0.5050 & & $\longrightarrow$ \\
\hline
\end{tabular}

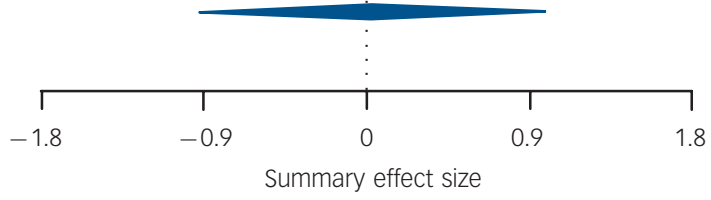

(b)

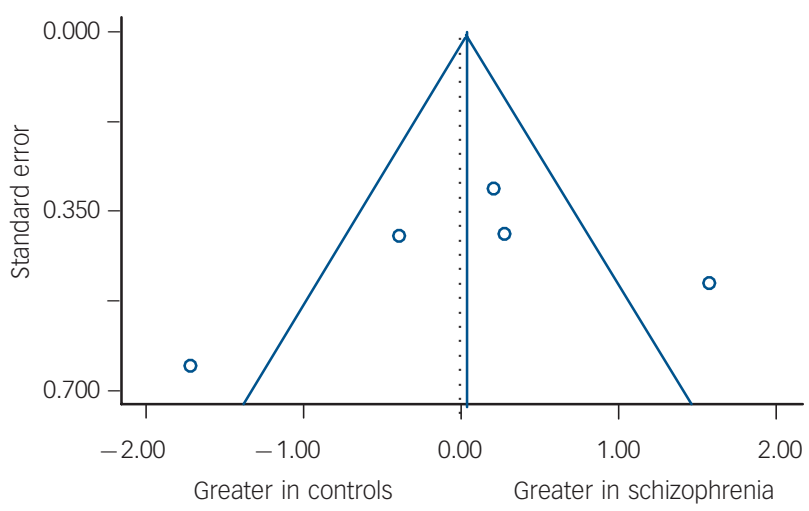

Estimated effect size (c)

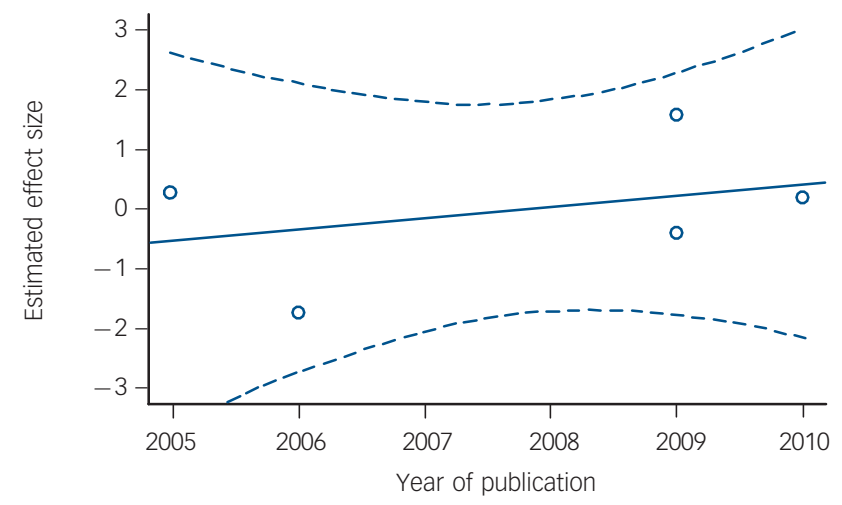

Fig. 3 (a) Forrest plot, (b) funnel plot and (c) meta-regression with year of publication of meta-analysis of $D_{2} / D_{3} B P_{N D}$ in the substantia nigra. Error bars represent 95\% confidence intervals; RE model, random-effects model.

is warranted, particularly in the thalamus given the potential reduction in $\mathrm{D}_{2} / \mathrm{D}_{3}$ receptor availability here.

\section{Dopamine synthesis capacity}

The majority of findings indicate there was no significant alteration in cortical dopamine synthesis capacity in schizophrenia, although there was both a large effect size reduction in one frontal cortical region and a large effect elevation in the posterior cingulate in the same study. However, the findings in the frontal cortex, and the negative findings in the temporal cortex and amygdala need to be considered in the context of the relatively low reliability of imaging dopamine synthesis capacity in these regions ${ }^{58}$ and evidence that radiolabelled DOPA does not give a specific PET signal in cortical regions. ${ }^{59}$ Importantly, Cropley et al ${ }^{59}$ found that there was greater uptake of [18F]-DOPA in white matter than grey matter in frontal cortex, and that partial volume correction for white matter reduced the $[18 \mathrm{~F}]-\mathrm{DOPA}$ uptake rate constant while increasing its variability. Thus, the cortical findings, both positive and null, need to be considered with these major caveats in mind. Further investigation of cortical dopamine synthesis would benefit from the development of more specific radiotracers.

\section{General methodological considerations}

Variation in the quality of studies is a potential source of bias in the meta-analyses. One important potential source of bias, particularly for small structures such as the substantia nigra, is the influence of partial volume effects. These become important for structures two to three times smaller than the resolution of the scanner. ${ }^{60,61}$ These effects include loss of signal in affected regions as well as spill-over from neighbouring structures. Where there is a loss of volume in a region, as there is in cortical regions in schizophrenia, ${ }^{62}$ this could bias group comparisons. Six of the studies examined whether there were differences in the volume of structures examined between the schizophrenia and controls 


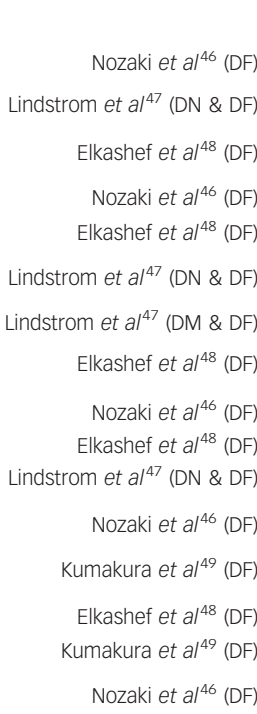

(C)

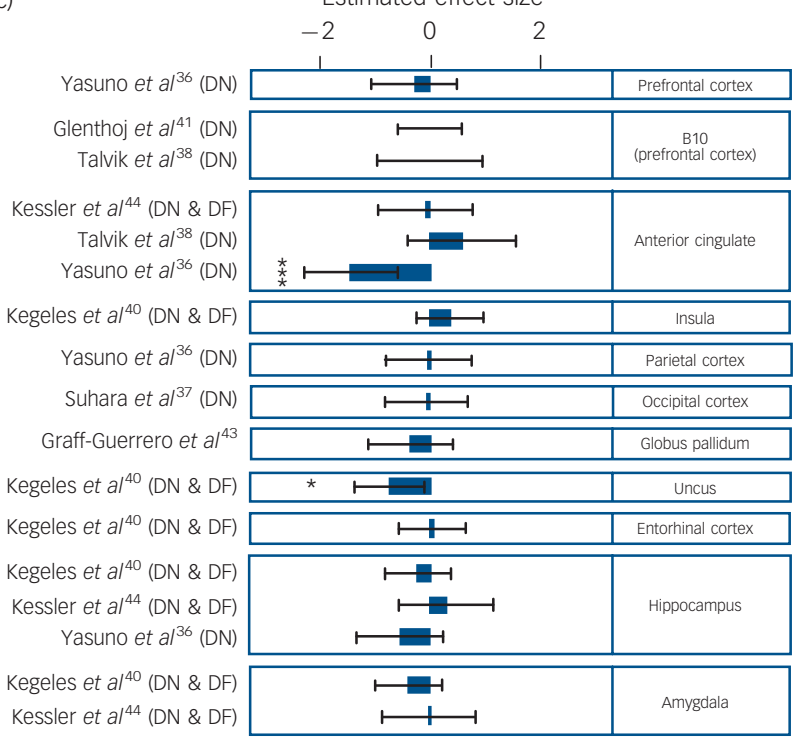

(b)

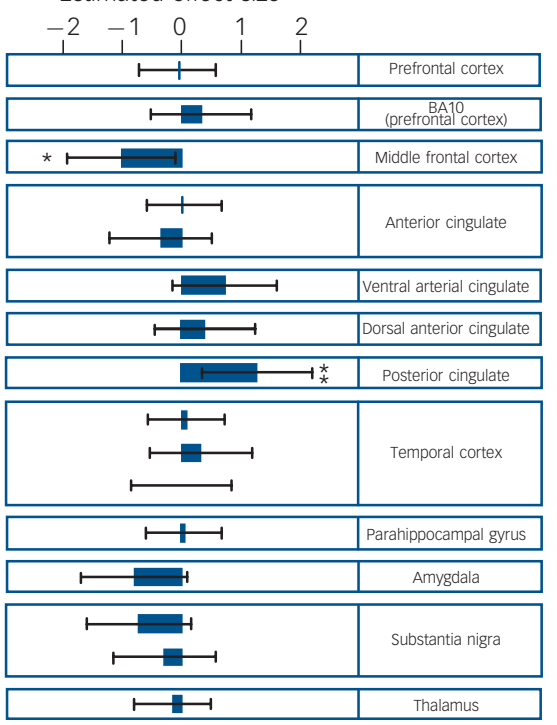

Estimated effect size

A
Okubo et al (DF) Abi-Dargham et al ${ }^{52}$ (DF \& DN) Karlsson et $a l^{51}(\mathrm{DN})$ Karlsson et al ${ }^{51}$ (DN) Karlsson et al ${ }^{51}$ (DN) Abi-Dargham et al ${ }^{52}$ (DN \& DF) Abi-Dargham et al ${ }^{52}$ (DN \& DF) Abi-Dargham et al ${ }^{52}$ (DN \& DF) Abi-Dargham et a/ ${ }^{52}$ (DN \& DF) Okubo et al ${ }^{50}$ (DN) Okubo et $a^{50}$ (Df) Abi-Dargham et $a^{52}$ (DN \& DF) Karlsson et $a l^{51}$ (DN) Abi-Dargham et al ${ }^{52}$ (DN \& DF)

(d)

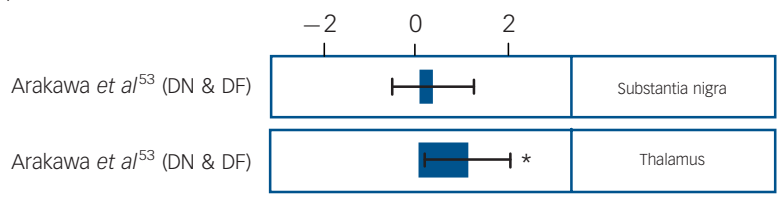

Fig. 4 Overview of the effect sizes found by (a) studies of presynaptic dopamine synthesis, (b) $D_{1}$ receptor studies, (c) $D_{2}$ receptor studies and (d) dopamine transporter (DAT) studies for different extrastriatal regions.

Error bars represent $95 \%$ confidence intervals. Significant changes are indicated by * for $P<0.05$, ** for $P<0.01$ and *** for $P<0.001$. Previous treatment of the patient sample is indicate by (DF) for drug-free and (DN) for drug-naive. Please note that the significance level plotted in Fig. 4 has not been corrected for multiple comparisons.

group - four found no difference, ${ }^{24-27,51}$ and two found a significant difference. ${ }^{28,43}$ However, only one study ${ }^{40}$ made use of partial volume correction methods to reduce the impact of partial volume effects. ${ }^{61,63}$ When this was applied in the uncus, for example, values changed markedly: there was a $109 \%$ increase in $\mathrm{D}_{2} / \mathrm{D}_{3} \mathrm{BP}_{\mathrm{ND}}$ in controls and an $88 \%$ increase in patients with schizophrenia. ${ }^{40}$ Type of illness may also be important, ${ }^{64}$ with evidence that patients whose condition is refractory do not show the same dopaminergic changes, for example, and this was not evaluated in the studies.

It is important to note that binding potential, the outcome measure in the receptor studies, depends on the density of receptors, affinity of the receptor for the radiotracer and occupancy by endogenous dopamine. Alterations in any one of these parameters could contribute to differences or, conceivably, if more than one parameter is affected in a condition, the net result could either be that they cancel each other out or are additive. ${ }^{65}$ Studies using techniques that enable separate measurements of receptor density $\left(B_{\max }\right)$, affinity $\left(1 / K_{\mathrm{d}}\right.$; where $K_{\mathrm{d}}$ is the dissociation constant for the radiotracer from the receptor) and intrasynaptic dopamine levels ${ }^{66-68}$ are needed to disentangle these issues. Although most $\mathrm{D}_{2} / \mathrm{D}_{3}$ receptor radiotracers we included in the meta-analyses have similar affinity for $\mathrm{D}_{2}$ and $\mathrm{D}_{3}$ receptors, PHNO, as used in Graff-Guerrero et al, ${ }^{43}$ has a higher affinity for $\mathrm{D}_{3}$ than $\mathrm{D}_{2}$ receptors, ${ }^{69}$ which means it is relatively less sensitive to $\mathrm{D}_{2}$ alterations.

For the meta-analyses it is important to note that the sample sizes were modest and, as meta-analytic results are less stable with smaller sample sizes, ${ }^{70}$ consequently may change significantly with the addition of future studies. Furthermore, it is advisable not to solely rely on significance tests to interpret results, but to also consider the summary effect size estimate and associated confidence 
interval. ${ }^{71}$ This is particularly the case as the meta-analyses lacked power to detect small differences. Finally, we found evidence of moderate to large heterogeneity in our meta-analyses (indicated by $I_{2}$ values greater than $50 \%$ ). However, the random-effects approach to meta-analysis we used is relatively robust to heterogeneity. ${ }^{34}$

\section{Implications and future directions}

An updated version of the dopamine hypothesis proposes that negative and cognitive symptoms of schizophrenia are secondary to cortical hypodopaminergia, whereas psychotic symptoms are secondary to subcortical hyperdopaminergia. ${ }^{7,8}$ In the past two decades consistent in vivo evidence has accrued for subcortical hyperdopaminergia, with a large effect size elevation in striatal dopamine synthesis and release in schizophrenia ${ }^{9}$ and potentially sufficient specificity to be a biomarker. ${ }^{72,73}$ In contrast, our metaanalysis of dopamine studies in cortical regions highlights the relative paucity of in vivo studies to support the hypothesis of reduced cortical dopaminergic function. This is surprising given how influential the hypothesis of cortical hypodopaminergia has been and the central role of dopamine-blocking drugs in the treatment of schizophrenia. ${ }^{74}$

Our finding of a small but not statistically significant reduction in $D_{2} / D_{3}$ availability in the thalamus contrasts with our previous findings in the striatum, where there was a small but inconsistent elevation. ${ }^{9}$ One potential explanation for this inconsistency is that there are group difference in the volumes of these structures which, if they were smaller in schizophrenia, would lead to lower values due to partial volume effects (see above).

Our results indicate that the initial report of a large reduction in thalamic $\mathrm{D}_{2} / \mathrm{D}_{3}$ receptor availability ${ }^{35}$ appears to have moderated into a non-significant reduction with subsequent reports. However, as the confidence interval includes -0.6 , it remains possible that there is a moderate-large effect size reduction in schizophrenia. Furthermore, given the finding of elevated thalamic dopamine transporter availability and the role of the thalamus in relaying sensory information, ${ }^{75}$ dopaminergic dysfunction here could plausibly play a role in the development of hallucinations and other psychotic symptoms. Thus, further investigation of thalamic dopamine function is warranted.

The substantia nigra is the location of the cell bodies of the dopamine neurons projecting to the striatum. As such the lack of alterations in dopamine transporter or $\mathrm{D}_{2} / \mathrm{D}_{3}$ availability in the nigra suggests there is no increase in dopamine neuron density or altered $D_{2} / D_{3}$ autoreceptor function underlying the striatal dopaminergic dysfunction seen in schizophrenia ${ }^{66,76-78}$ and its prodrome. $^{79,80}$ Taken with evidence for altered dopamine synthesis capacity in the nigra, ${ }^{81}$ this suggests there is increased nigral dopamine function but no compensatory change in nigral $\mathrm{D}_{2} / \mathrm{D}_{3}$ receptors.

A fundamental issue that remains to be established is whether there is reduced cortical dopamine release in schizophrenia. Although the relatively lower density of dopamine receptors in cortical regions has made this more challenging to study than in the striatum, ${ }^{65}$ evidence from some, ${ }^{69,82-85}$ although not all, ${ }^{86-92}$ of the studies with high affinity $\mathrm{D}_{2} / \mathrm{D}_{3}$ selective radiotracers indicates that this is possible with sufficient reliability for group comparisons. There is, thus, the potential to test this unresolved aspect of the dopamine hypothesis in vivo in future studies. Finally, there has been relatively little in vivo investigation of the upstream and downstream regulation of dopaminergic signalling in schizophrenia; both of which are needed to understand the nature of dopaminergic dysfunction in the disorder. ${ }^{93,94}$

\section{Implications}

Despite the wide influence of the cortical dopamine hypofunction hypothesis and the central role of dopamine blockade in the treatment of schizophrenia, there is relatively limited direct evidence of altered dopaminergic function in cortical and other extrastriatal regions in schizophrenia. In this context it is worth remembering that secondary indices (such as reduced blood flow or altered frontal activation) are not a substitute for direct evidence. The available data are inconclusive and further investigation is warranted to determine whether there are alterations in thalamic $D_{2} / D_{3}$ receptors, and in $D_{1}$ receptor availability, dopamine synthesis capacity and dopamine transporter availability.

\footnotetext{
Joseph Kambeitz, MD, Department of Psychosis Studies, Institute of Psychiatry, King's College London, UK; Anissa Abi-Dargham, MD, Department of Psychiatry, Columbia University, New York State Psychiatric Institute, New York, USA;

Shitij Kapur, MD, PhD, Department of Psychosis Studies, Institute of Psychiatry,

Shitij Kapur, MD, PhD, Department of Psychosis Studies, Institute of Psychiatry,
King's College London, UK; Oliver D. Howes, BM, BCh, MA, MRCPsych, PhD, DM, Department of Psychosis Studies, Institute of Psychiatry, King's College London, and Psychiatric Imaging Group, Medical Research Council Clinical Sciences Centre, Imperial College London, Hammersmith Hospital, UK

Correspondence: Oliver D. Howes, BM, BCh, MA, MRCPsych, PhD, DM, Department of Psychosis Studies, Institute of Psychiatry, King's College London, PO Box 67, Camberwell, London SE5 8AF, UK. Email: oliver.howes@kcl.ac.uk

First received 17 May 2013, final revision 17 Oct 2013, accepted 19 Dec 2013
}

\section{Funding}

This study was funded by a Medical Research Council (UK) grant to O.D.H. (grant number: MC-A656-5QD30) and the National Institute of Health Research Biomedical Research Council.

\section{References}

1 American Psychiatric Association. APATF on Diagnostic and Statistical Manual of Mental Disorders: DSM-IV-TR. American Psychiatric Publishing, 2000

2 Lopez AD. Global Burden of Disease and Risk Factors. Oxford University Press, 2006

3 McGuire P, Howes OD, Stone J, Fusar-Poli P. Functional neuroimaging in schizophrenia: diagnosis and drug discovery. Trends Pharmacol Sci 2008; 29 91-8.

4 Lewis DA, Gonzalez-Burgos G. Pathophysiologically based treatment interventions in schizophrenia. Nat Med 2006; 12: 1016-22.

5 Meltzer HY, Stahl SM. The dopamine hypothesis of schizophrenia: a review. Schizophr Bull 1976; 2: 19-76.

6 Van Rossum JM. The significance of dopamine-receptor blockade for the mechanism of action of neuroleptic drugs. Arch Int Pharmacodyn Ther 1966; 160: $492-4$.

7 Davis KL, Kahn RS, Ko G, Davidson M. Dopamine in schizophrenia: a review and reconceptualization. Am J Psychiatry 1991; 148: 1474-86.

8 Howes OD, Kapur S. The dopamine hypothesis of schizophrenia: version III - the final common pathway. Schizophr Bull 2009; 35: 549-62.

9 Howes OD, Kambeitz J, Kim E, Stahl D, Slifstein M, Abi-Dargham A, et al. The nature of dopamine dysfunction in schizophrenia and what this means for treatment. Arch Gen Psychiatry 2012; 69: 776-86.

10 Abi-Dargham A. Do we still believe in the dopamine hypothesis? New data bring new evidence. Int J Neuropsychopharmacol 2004; 7 (suppl 1): S1-5.

11 Wong DF, Wagner Jr HN, Tune LE, Dannals RF, Pearlson GD, Links JM, et al. Positron emission tomography reveals elevated D2 dopamine receptors in drug-naive schizophrenics. Science 1986; 234: 1558-63.

12 Farde L, Halldin C, Stone-Elander S, Sedvall G. PET analysis of human dopamine receptor subtypes using 11C-SCH 23390 and 11C-raclopride. Psychopharmacology (Berl) 1987; 92: 278-84.

13 Reith J, Benkelfat C, Sherwin A, Yasuhara Y, Kuwabara H, Andermann F, et al. Elevated dopa decarboxylase activity in living brain of patients with psychosis. Proc Natl Acad Sci USA 1994; 91: 11651-4. 
14 Halldin C, Farde L, Högberg T, Mohell N, Hall H, Suhara T, et al. Carbon-11 FLB 457: a radioligand for extrastriatal D2 dopamine receptors. J NuCl Med 1995; 36: 1275-81.

15 Mukherjee J, Yang ZY, Brown $T$, Lew $R$, Wernick $M$, Ouyang $X$, et al. Preliminary ass essment of extrastriatal dopamine D-2 receptor binding in the rodent and nonhuman primate brains using the high affinity radioligand 18F-fallypride. NuCl Med Biol 1999; 26: 519-27.

16 Kessler RM, Mason NS, Votaw JR, De Paulis T, Clanton JA, Ansari MS, et al. Visualization of extrastriatal dopamine D2 receptors in the human brain. Eur J Pharmacol 1992; 223: 105-7.

17 Martin GE, Williams M, Pettibone DJ, Zrada MM, Lotti VJ, Taylor DA, et al. Selectivity of (+)-4-propyl-9-hydroxynaphthoxazine [(+)-PHNO] for dopamine receptors in vitro and in vivo. J Pharmacol Exp Ther 1985; 233: 395-401.

18 Elsinga PH, Hatano K, Ishiwata K. PET tracers for imaging of the dopaminergic system. Curr Med Chem 2006; 13: 2139-53.

19 Sedvall G, Pauli S, Karlsson P, Farde L, Nordström AL, Nyberg S, et al. PET imaging of neuroreceptors in schizophrenia. Eur Neuropsychopharmacol 1995; 5 (suppl): 25-30.

20 Farde L, Wiesel FA, Halldin C, Sedvall G. Central D2-dopamine receptor occupancy in schizophrenic patients treated with antipsychotic drugs. Arch Gen Psychiatry 1988; 45: 71-6.

21 Abi-Dargham A, Xu X, Thompson JL, Gil R, Kegeles LS, Urban N, et al. Increased prefrontal cortical $D_{1}$ receptors in drug naive patients with schizophrenia: a PET study with $\left[{ }^{11} \mathrm{C}\right] \mathrm{NNC} 112$. J Psychopharmacol (Oxford) 2012; 26: 794-805

22 Ioannidis J, Lau J. Evolution of treatment effects over time: empirical insight from recursive cumulative metaanalyses. Proc Natl Acad Sci USA 2001; 98 831-6.

23 The R Development Core Team. R: A Language and Environment for Statistical Computing. R Foundation for Statistical Computing, 2010.

24 Viechtbauer W. Conducting meta-analyses in $\mathrm{R}$ with the metafor package. J Stat Softw 2010; 36: 1-48.

25 Champely S. pwr: Basic Functions for Power Analysis. $R$ Package Version 1.1.1. R Project, 2009 (http://CRAN.R-project.org/package\&equalspwr).

26 Hedges LV, Olkin I. Statistical Methods for Meta-Analysis. Academic Press, 1985.

27 Hedges LV, Vevea JL. Fixed-and random-effects models in meta-analysis. Psychol Methods 1998; 3: 486.

28 Raudenbusch S. Analysing effect sizes: random effects models. In The Handbook of Research Synthesis and Meta-Analysis (2nd edn) (eds H Cooper, LV Hedges, JC Valentine): 295-315. Russell Sage Foundation, 2009.

29 Higgins J, Thompson SG, Deeks JJ, Altman DG. Measuring inconsistency in meta-analyses. BMJ 2003; 327: 557.

30 Higgings JPT, Green S. Cochrane Handbook for Systematic Reviews of Interventions (Version 5.1.0). Cochrane Collaboration, 2011 (http:// handbook.cochrane.org/).

31 Egger M, Smith GD, Schneider M, Minder C. Bias in meta-analysis detected by a simple, graphical test. BMJ 1997; 315: 629.

32 Innis RB, Cunningham VJ, Delforge J, Fujita M, Gjedde A, Gunn RN, et al. Consensus nomenclature for in vivo imaging of reversibly binding radioligands. J Cereb Blood Flow Metab 2007; 27: 1533-9.

33 Buchsbaum MS, Christian BT, Lehrer DS, Narayanan TK, Shi B, Mantil J, et al. D2/D3 dopamine receptor binding with [F-18]fallypride in thalamus and cortex of patients with schizophrenia. Schizophr Res 2006; 85: 232-44.

34 Lehrer DS, Christian BT, Kirbas C, Chiang M, Sidhu S, Short H, et al. 18F-fallypride binding potential in patients with schizophrenia compared to healthy controls. Schizophr Res 2010; 122: 43-52.

35 Yasuno $F$, Suhara $T$, Okubo $Y$, sudo $Y$, Inoue $M$, Ichimiya $T$, et al. Low dopamine $d(2)$ receptor binding in subregions of the thalamus in schizophrenia. Am J Psychiatry 2004; 161: 1016-22.

36 Yasuno F, Suhara T, Okubo Y, Ichimiya T, Takano A, Sudo Y, et al. Abnormal effective connectivity of dopamine D2 receptor binding in schizophrenia. Psychiatry Res 2005; 138: 197-207.

37 Suhara $T$, Okubo $Y$, Yasuno $F$, Sudo $Y$, Inoue $M$, Ichimiya $T$, et al. Decreased dopamine D2 receptor binding in the anterior cingulate cortex in schizophrenia. Arch Gen Psychiatry 2002; 59: 25-30.

38 Talvik M, Nordström A-L, Olsson H, Halldin C, Farde L. Decreased thalamic D2/D3 receptor binding in drug-naive patients with schizophrenia: a PET study with [11C]FLB 457. Int J Neuropsychopharmacol 2003; 6: 361-70.

39 Talvik M, Nordström A-L, Okubo Y, Olsson H, Borg J, Halldin C, et al. Dopamine D2 receptor binding in drug-naïve patients with schizophrenia examined with raclopride-C11 and positron emission tomography. Psychiatry Res 2006; 148: 165-73.
40 Kegeles LS, Slifstein M, Xu X, Urban N, Thompson JL, Moadel T, et al. Striatal and extrastriatal dopamine D2/D3 receptors in schizophrenia evaluated with [18F]fallypride positron emission tomography. Biol Psychiatry 2010; 68: 634-41.

41 Glenthoj BY, Mackeprang T, Svarer C, Rasmussen H, Pinborg LH, Friberg L, et al. Frontal dopamine $D(2 / 3)$ receptor binding in drug-naive first-episode schizophrenic patients correlates with positive psychotic symptoms and gender. Biol Psychiatry 2006; 60: 621-9.

42 Tuppurainen $\mathrm{H}$, Kuikka JT, Laakso MP, Viinamäki H, Husso M, Tiihonen J. Midbrain dopamine D2/3 receptor binding in schizophrenia. Eur Arch Psychiatry Clin Neurosci 2006; 256: 382-7.

43 Graff-Guerrero A, Mizrahi R, Agid O, Marcon H, Barsoum P, Rusjan P, et al. The dopamine D2 receptors in high-affinity state and D3 receptors in schizophrenia: a clinical [11C]-(+)-PHNO PET study. Neuropsychopharmacology 2009; 34: 1078-86.

44 Kessler RM, Woodward ND, Riccardi P, Li R, Ansari MS, Anderson S, et al. Dopamine D2 receptor levels in striatum, thalamus, substantia nigra, limbic regions, and cortex in schizophrenic subjects. Biol Psychiatry 2009; 65: 1024-31.

45 Tuppurainen H, Kuikka J, Viinamäki H, Husso-Saastamoinen M, Bergström K, Tiihonen J. Extrastriatal dopamine D 2/3 receptor density and distribution in drug-naive schizophrenic patients. $\mathrm{Mol}$ Psychiatry 2003; 8: 453-5.

46 Nozaki S, Kato M, Takano $H$, Ito $H$, Takahashi $H$, Arakawa $R$, et al. Regional dopamine synthesis in patients with schizophrenia using L-[beta-11C]DOPA PET. Schizophr Res 2009; 108: 78-84.

47 Lindström LH, Gefvert O, Hagberg G, Lundberg T, Bergström M, Hartvig P, et al. Increased dopamine synthesis rate in medial prefrontal cortex and striatum in schizophrenia indicated by L-(beta-11C) DOPA and PET. Biol Psychiatry 1999; 46: 681-8.

48 Elkashef AM, Doudet D, Bryant T, Cohen RM, Li SH, Wyatt RJ. 6-(18)F-DOPA PET study in patients with schizophrenia. Positron emission tomography. Psychiatry Res 2000; 100: 1-11.

49 Kumakura Y, Cumming P, Vernaleken I, Buchholz H-G, Siessmeier T, Heinz A, et al. Elevated [18F]fluorodopamine turnover in brain of patients with schizophrenia: an [18F]fluorodopa/positron emission tomography study. J Neurosci 2007; 27: 8080-7.

50 Okubo Y, Suhara T, Suzuki K, Kobayashi K, Inoue O, Terasaki O, et al. Decreased prefrontal dopamine D1 receptors in schizophrenia revealed by PET. Nature 1997; 385: 634-6.

51 Karlsson P, Farde L, Halldin C, Sedvall G. PET study of D(1) dopamine receptor binding in neuroleptic-naive patients with schizophrenia. Am J Psychiatry 2002; 159: 761-7.

52 Abi-Dargham A, Mawlawi O, Lombardo I, Gil R, Martinez D, Huang Y, et al. Prefrontal dopamine D1 receptors and working memory in schizophrenia. $J$ Neurosci 2002; 22: 3708-19.

53 Arakawa $\mathrm{R}$, Ichimiya $\mathrm{T}$, Ito $\mathrm{H}$, Takano A, Okumura $\mathrm{M}$, Takahashi $\mathrm{H}$, et al. Increase in thalamic binding of [(11)C]PE2I in patients with schizophrenia: a positron emission tomography study of dopamine transporter. J Psychiatr Res 2009; 43: 1219-23.

54 Guo N, Hwang D-R, Lo E-S, Huang Y-Y, Laruelle M, Abi-Dargham A. Dopamine depletion and in vivo binding of PET D1 receptor radioligands: implications for imaging studies in schizophrenia. Neuropsychopharmacology 2003; 28 : 1703-11.

55 Lidow MS, Goldman-Rakic PS. A common action of clozapine, haloperidol, and remoxipride on D1- and D2-dopaminergic receptors in the primate cerebral cortex. Proc Natl Acad Sci USA 1994; 91: 4353-6.

56 Ekelund J, Slifstein M, Narendran R, Guillin O, Belani H, Guo N-N, et al. In vivo DA D(1) receptor selectivity of NNC 112 and SCH 23390. Mol Imaging Biol 2007; 9: 117-25.

57 Hirvonen J, Johansson J, Teräs M, Oikonen V, Lumme V, Virsu P, et al. Measurement of striatal and extrastriatal dopamine transporter binding with high-resolution PET and [11C]PE2l: quantitative modeling and test-retest reproducibility. J Cereb Blood Flow Metab 2008; 28: 1059-69.

58 Egerton A, Demjaha A, McGuire P, Mehta MA, Howes OD. The test-retest reliability of 18F-DOPA PET in assessing striatal and extrastriatal presynaptic dopaminergic function. Neuroimage 2010; 50: 524-31.

59 Cropley VL, Fujita M, Bara-Jimenez W, Brown AK, Zhang X-Y, Sangare J, et al. Pre- and post-synaptic dopamine imaging and its relation with frontostriatal cognitive function in Parkinson disease: PET studies with [11C]NNC 112 and [18F]FDOPA. Psychiatry Res 2008; 163: 171-82.

60 Rousset OG, Ma Y, Evans AC. Correction for partial volume effects in PET: principle and validation. J NuCl Med 1998; 39: 904-11.

$61 \mathrm{Kim}$ E, Shidahara M, Tsoumpas C, McGinnity CJ, Kwon JS, Howes OD, et al. Partial volume correction using structural-functional synergistic resolution recovery: comparison with geometric transfer matrix method. J Cereb Blood Flow Metab 2013; 33: 914-20. 
62 Fornito A, Yücel M, Patti J, Wood SJ, Pantelis C. Mapping grey matter reductions in schizophrenia: an anatomical likelihood estimation analysis of voxel-based morphometry studies. Schizophr Res 2009; 108: 104-13.

63 Rousset OG, Collins DL, Rahmim A, Wong DF. Design and implementation of an automated partial volume correction in PET: application to dopamine receptor quantification in the normal human striatum. J NuCl Med 2008; 49 1097-106.

64 Demjaha A, Murray RM, McGuire PK, Kapur S, Howes OD. Dopamine synthesis capacity in patients with treatment-resistant schizophrenia. Am J Psychiatry 2012; 169: 1203-10.

65 Egerton A, Mehta MA, Montgomery AJ, Lappin JM, Howes OD, Reeves SJ et al. The dopaminergic basis of human behaviors: a review of molecular imaging studies. Neurosci Biobehav Rev 2009; 33: 1109-32.

66 Abi-Dargham A, Rodenhiser J, Printz D, Zea-Ponce Y, Gil R, Kegeles LS, et al. Increased baseline occupancy of D2 receptors by dopamine in schizophrenia. Proc Natl Acad Sci USA 2000; 97: 8104-9.

67 Kuwabara H, McCaul ME, Wand GS, Earley CJ, Allen RP, Weerts EM, et al. Dissociative changes in the Bmax and KD of dopamine D2/D3 receptors with aging observed in functional subdivisions of the striatum: a revisit with an improved data analysis method. J NuCl Med 2012; 53: 805-12.

68 Hietala J, Någren K, Lehikoinen P, Ruotsalainen U, Syvälahti E. Measuremen of striatal D2 dopamine receptor density and affinity with [11C]-raclopride in vivo: a test-retest analysis. J Cereb Blood Flow Metab 1999; 19: 210-7.

69 Narendran R, Slifstein M, Guillin O, Hwang Y, Hwang D-R, Scher E, et al. Dopamine (D2/3) receptor agonist positron emission tomography radiotracer [11C]-(+)-PHNO is a D3 receptor preferring agonist in vivo. Synapse 2006; 60 485-95.

70 Trikalinos TA, Churchill R, Ferri $\mathrm{M}$, Leucht $\mathrm{S}$, Tuunainen A, Wahlbeck $\mathrm{K}$, et a Effect sizes in cumulative meta-analyses of mental health randomized trials evolved over time. J Clin Epidemiol 2004; 57: 1124-30.

71 Stang A. Low P-values exclude nothing, and P-values are no substitute for measures of effect. J Clin Epidemiol 2011; 64: 452-453; author reply 453

72 Bose SK, Turkheimer FE, Howes OD, Mehta MA, Cunliffe R, Stokes PR, et al. Classification of schizophrenic patients and healthy controls using [18F] fluorodopa PET imaging. Schizophr Res 2008; 106: 148-55.

73 Howes OD, Montgomery AJ, Asselin M-C, Murray RM, Grasby PM, McGuire PK. Molecular imaging studies of the striatal dopaminergic system in psychosis and predictions for the prodromal phase of psychosis. $\mathrm{Br} J$ Psychiatry 2007; 191 (suppl 51): s13-8.

74 Howes OD, Egerton A, Allan V, McGuire P, Stokes P, Kapur S. Mechanisms underlying psychosis and antipsychotic treatment response in schizophrenia: insights from PET and SPECT imaging. Curr Pharm Des 2009; 15: 2550-9.

75 Sánchez-González MA, García-Cabezas MA, Rico B, Cavada C. The primate thalamus is a key target for brain dopamine. J Neurosci 2005; 25: 6076-83.

76 Laruelle M, Abi-Dargham A, van Dyck CH, Gil R, D'Souza CD, Erdos J, et al. Single photon emission computerized tomography imaging of amphetamineinduced dopamine release in drug-free schizophrenic subjects. Proc Nat Acad Sci USA 1996; 93: 9235-40.

77 Breier A, Su TP, Saunders R, Carson RE, Kolachana BS, de Bartolomeis A, et al. Schizophrenia is associated with elevated amphetamine-induced synaptic dopamine concentrations: evidence from a novel positron emission tomography method. Proc Natl Acad Sci USA 1997; 94: 2569-74.

78 Howes OD, Montgomery AJ, Asselin M-C, Murray RM, Valli I, Tabraham P, et al. Elevated striatal dopamine function linked to prodromal signs of schizophrenia. Arch Gen Psychiatry 2009; 66: 13-20.
79 Howes O, Bose S, Turkheimer F, Valli I, Egerton A, Stahl D, et al. Progressive increase in striatal dopamine synthesis capacity as patients develop psychosis: a PET study. Mol Psychiatry 2011; 16: 885-6.

80 Mizrahi R, Addington J, Rusjan PM, Suridjan I, Ng A, Boileau I, et al. Increased stress-induced dopamine release in psychosis. Biol Psychiatry 2012; 71: 561-7.

81 Howes OD, Williams M, Ibrahim K, Leung G, Egerton A, McGuire PK, et al. Midbrain dopamine function in schizophrenia and depression: a post-mortem and positron emission tomographic imaging study. Brain 2013; 136: 3242-51.

82 Narendran R, Mason NS, May MA, Chen C-M, Kendro S, Ridler K, et al. Positron emission tomography imaging of dopamine $D_{2} / 3$ receptors in the human cortex with $\left[{ }^{11} \mathrm{C}\right] \mathrm{FLB}$ 457: reproducibility studies. Synapse $2011 ; 65$ $35-40$.

83 Montgomery AJ, Asselin M-C, Farde L, Grasby PM. Measurement of methylphenidate-induced change in extrastriatal dopamine concentration using [11C]FLB 457 PET. J Cereb Blood Flow Metab 2007; 27: 369-77.

84 Riccardi P, Li R, Ansari MS, Zald D, Park S, Dawant B, et al. Amphetamineinduced displacement of [18F] fallypride in striatum and extrastriatal regions in humans. Neuropsychopharmacology 2006; 31: 1016-26.

85 Chou YH, Halldin C, Farde L. Effect of amphetamine on extrastriatal D2 dopamine receptor binding in the primate brain: a PET study. Synapse 2000; 38: $138-43$

86 Mukherjee J, Christian BT, Narayanan TK, Shi B, Collins D. Measurement of d-amphetamine-induced effects on the binding of dopamine D-2/D-3 receptor radioligand, $18 \mathrm{~F}$-fallypride in extrastriatal brain regions in non-human primates using PET. Brain Res 2005; 1032: 77-84.

87 Slifstein $M$, Narendran R, Hwang D-R, Sudo $Y$, Talbot PS, Huang $Y$, et al Effect of amphetamine on [(18)F]fallypride in vivo binding to $D(2)$ receptors in striatal and extrastriatal regions of the primate brain: single bolus and bolus plus constant infusion studies. Synapse 2004; 54: 46-63.

88 Aalto S, Brück A, Laine M, Någren K, Rinne Jo. Frontal and temporal dopamine release during working memory and attention tasks in healthy humans: a positron emission tomography study using the high-affinity dopamine D2 receptor ligand [11C]FLB 457. J Neurosci 2005; 25: 2471-7.

89 Okauchi T, Suhara T, Maeda J, Kawabe K, Obayashi S, Suzuki K. Effect of endogenous dopamine on endogenous dopamine on extrastriated [11C]FLB 457 binding measured by PET. Synapse 2001; 41: 87-95.

90 Tsukada H, Harada N, Nishiyama S, Fukumoto D, Kakiuchi T. Acute NMDA receptor antagonism induces biphasic striatal utilization of L-[beta-11C]DOPA: PET studies in the conscious monkey brain. Synapse 2005; 57: 116-9.

91 Cropley VL, Innis RB, Nathan PJ, Brown AK, Sangare JL, Lerner A, et al. Small effect of dopamine release and no effect of dopamine depletion on [18F]fallypride binding in healthy humans. Synapse 2008; 62: 399-408.

92 Frankle WG, Mason NS, Rabiner EA, Ridler K, May MA, Asmonga D, et al No effect of dopamine depletion on the binding of the high-affinity $D 2 / 3$ radiotracer [11C]FLB 457 in the human cortex. Synapse 2010; 64: 879-85.

93 Stone JM, Howes OD, Egerton A, Kambeitz J, Allen P, Lythgoe DJ, et al. Altered relationship between hippocampal glutamate levels and striatal dopamine function in subjects at ultra high risk of psychosis. Biol Psychiatry 2010; 68: 599-602.

94 Blasi G, Napolitano F, Ursini G, Taurisano P, Romano R, Caforio G, et al. DRD2/AKT1 interaction on D2 C-AMP independent signaling, attentional processing, and response to olanzapine treatment in schizophrenia. Proc Natl Acad Sci USA 2011; 108: 1158-63. 